\title{
Gender-Based Violence: A Crucial Challenge for Public Health Sanjel S
}

Department of Community Medicine

Kathmandu University School of Medical sciences Dhulikhel, Kavre

\section{Corresponding Author}

Seshananda Sanjel

Department of Community Medicine

Kathmandu University School of Medical sciences Dhulikhel, Kavre

E-mail: sanjel.sn@gmail.com

\section{Citation}

Sanjel S. Gender-Based Violence: A Crucial Challenge for Public Health. Kathmandu Univ Med J 2013;42(2):179-184.

\begin{abstract}
This article attempts to summarize the situations of gender-based violence, a major public health issue. Due to the unequal power relations between men and women, women are violated either in family, in the community or in the State. Gender-based violence takes different forms like physical, sexual or psychological/ emotional violence. The causes of gender-based violence are multidimensional including social, economic, cultural, political and religious. The literatures written in relation to the gender-based violence are accessed using electronic databases as PubMed, Medline and Google scholar, Google and other Internet Websites between 1994 and first quarter of 2013. The keywords such as gender-based violence, women violence, domestic violence, wife abuse, violence during pregnancy, women sexual abuse, political gender based violence, cultural gender-based violence, economical gender-based violence, child sexual abuse and special forms of genderbased violence in Nepal were used for internet search. As GBVs remain one of the most rigorous challenges of women's health and well-being, it is one of the indispensable issues of equity and social justice. To create a gender-based violence free environment, a lot works has to be done. Hence, it is suggested to provide assistance to the victims of violence developing the mechanism to support them.
\end{abstract}

\section{KEYWORDS}

Gender-based violence, sexual violence, special forms of gender-based violence in Nepal, women violence

\section{INTRODUCTION}

Gender-based violence (GBV) is a major public health and human rights concern throughout the world. ${ }^{1,2}$ GBVs include any act of verbal or physical force, coercion or life-threatening deprivation, directed at an individual woman or girl that causes physical or psychological harm, humiliation, or arbitrary deprivation of liberty and that perpetuates female subordination. ${ }^{3}$ GBVs arise from unequal power relations between men and women and continue to be reinforced by the entrenched patriarchal values system of identifying women as inferior to men which prevail illiteracy, poverty, and low status of women in the society. ${ }^{4,5}$ The GBVs take different forms for example physical, sexual, and psychological/ emotional., ${ }^{2,4}$ The domestic violence remains common in all demographic groups. ${ }^{6}$ A history of alcohol abuse, violence in the abuser's family of origin, emotional insecurity, antisocial features, borderline personality disorders, youthfulness, low educational attainment and low socioeconomic status all put an individual at risk of becoming abusive for men, and past witnessing of their father beating their mother, poor mental health and poor family work status exaggerate the circumstances of being abused for women. ${ }^{6,7} \mathrm{GBV}$ is a considerable cause of female morbidity and mortality and it has only recently begun to be recognized as an issue for public health. ${ }^{4,6,7}$ Whereas, Nepal has made strong normative and legal commitments to ending genderbased violence and ratified international conventions/ treaties, recent events painfully illustrate it is time for concrete national action with effective implementation and reinforcement of commitments, norms and laws. ${ }^{8}$ Moreover, gender-based violence is recognized and addressed as a prime barrier to reproductive health. ${ }^{9}$

\section{METHODS}

This article reviews the literature in gender-based violence. A major public health issue is highlighted, and challenges and key issues and implications were proposed. Electronic databases such as PubMed, Medline and Google scholar were searched to get scientific articles. For specific points, not accessible in the scientific literature Google and other Internet Websites were searched to access the articles between 1994 and first quarter of 2013. Documents published on World Health Organization (WHO), United Nations Population Fund (UNFPA), Ministry of Health (MoH) websites were also accessed to assess relevant reports and papers. Published and unpublished organizational reports, relevant articles and some grey literature were also 
included in this article. The computerized database were used to search the articles which were related to genderbased violence using an internet search from the following keywords: gender-based violence, women violence, domestic violence, wife abuse, violence during pregnancy, women sexual abuse, political gender based violence, cultural gender-based violence, economical gender-based violence, child sexual abuse and special forms of genderbased violence in Nepal.

\section{Gender Based Violence}

GBV is widespread cutting across classes, races, ages, religions and national boundaries. ${ }^{10,11}$ Women are facing violence at home, work place, market, road, bus, school, campus, hotel, office, law, policy, program, health, business and court and so on. ${ }^{12,13}$ Persistent patriarchy and dominance of Hindu religion and culture has treated women as a second class citizen from the very beginning. Furthermore, Hindu scripture also suggest that fathers, husbands and even sons should control women. ${ }^{13}$

Gender-based violence take many forms: 1) Physical abuse for example hitting, slapping/ biting/ shoving, destroying her property, using a weapon/ other objects to threaten or hurt her and denying her access to a health care provider. Sexual violence usually coincides with the physical violence. 2) Psychological/ emotional abuse for example threatening to take the children away from her, the threat could be to leave with the children or to call child protection services, stalking/ harassing her, controlling her time and what she does, isolating her from family/ friends and threatening to hurt someone she cares for. 3) Verbal abuse for example calling her names, other verbal means of attacking her self-esteem and humiliating her in the presence of others. 4) Sexual abuse for example denying sexual intimacy or forcing her into unwanted sexual acts, forcing her to get pregnant or to have an abortion and infecting her with sexually transmitted infections. 5) Spiritual abuse for example belittling her spiritual beliefs and not allowing her to attend the place of worship of her choice. 6) Financial abuse for example limiting access to family finances. ${ }^{14-16}$

Abuse against women happens because abusers have learned to be abusive by watching others in the family and society; abusers have found that it is an effective way of establishing or regaining control; societal attitudes and norms support the use of violence to control others; and powerful gender-based inequalities in society support the notion that woman abuse is a private matter and permit people to look the other way when it happens. ${ }^{14,17,18}$ Hence, most of the time, women are more often assaulted by someone known to the family, correspondingly pregnancy does not cause abuse but it is clearly a risk period associated with this. ${ }^{14,19}$

The violence is commonly experienced by women at various phases of the life cycle from prenatal period, infancy, childhood, adolescence, reproductive age to old age in different forms. ${ }^{4,13}$ The victims of sexual abuse, rape and domestic violence are at increased risk of suicide, depression, drug and alcohol abuse, STDs, HIV/ AIDS, hypertension, chronic pelvic pain, irritable bowel syndrome, asthma, gynecological problems, and a variety of psychiatric disorders. ${ }^{4,12,20-22}$ In addition, the raped women are rejected by their families and their communities, among them those who had a child from rape, widowhood, husband abandonment and gang rape have more risk of rejection. ${ }^{23}$ Besides, rape results not only in physical and psychological trauma, but can destroy family and community structures. ${ }^{23,24}$

\section{Gender-based Violence in the Family level}

Gender-based Violence in the Family is also known as the domestic violence, in which social, economic, and gender issues are increasingly recognized as significant factors. ${ }^{11}$ In domestic violence, women are vulnerable to infanticide, genital mutilation, a child's marriage without her consent, dowry-related violence, battering and sexual abuse. ${ }^{15,16}$ There are other additional causes of GBV in the family for example Inter-caste marriage, husband listen to other family members, sexual dissatisfaction, unemployment, polygamy, extramarital relation of husband, suspicious attitude, gambling, dowry and widowhood resulting in psychological abuse, physical violence and, sexual abuse and harassment. Surprisingly, the main perpetrator is the intimate partner and the family members. ${ }^{25}$ The husband is the most common perpetrator and the sexual domestic violence is increased with increased age, employed for cash and marital relationship (divorced, separated, or widowed) with the next most common is a former husband, sometimes a stranger and occasionally a relative. ${ }^{16,26}$ Women's risk of physical and sexual violence is related to traditional gender norms for example husbands' age, education level, women's economic independence, husbands' being unfaithful, husbands' using alcohol, husbands' fighting with other men, husbands' having witnessed domestic violence as a child and living in rural areas. ${ }^{26-29}$ The women experience different types of health problem due to domestic violence for example chronic conditions like irritable bowel syndrome and chronic pain syndrome; mental health problem, reproductive health problem, physical health problem due to severe beating, backache, problem in vision and poor subjective health and the women even initiate negative health behavior like start to smoke and take alcohol. ${ }^{20,30}$

\section{Violence during Pregnancy}

Studies revealed that GBV often gets worse during pregnancy occurring more frequently than placenta praevia or gestational diabetes. ${ }^{14}$ Women who are pregnant may be abused by their current or ex-husbands, partners, lovers or boyfriends, or by their caregivers, parents, siblings, children or other relatives for example the in-laws. ${ }^{14,29}$ The contributing factors for the violence during pregnancy are women's education, husband's education/ occupation, parity, birth order/ interval, unintended pregnancy, age of 
women at marriage/ pregnancy, ethnicity/ caste/ religion, family size/ structure, women's status in the household, and women's knowledge/ attitude/ belief/ culture. ${ }^{31,32}$ Experts and abuse survivors have suggested a wide variety of explanations for examples the abuser is jealous towards the fetus considering the fetus an interloper in the relationship, feels loss of power and control over a woman, dislike a woman's increased attention from family and health care providers during pregnancy. Moreover, the abuse during pregnancy is caused by stress related to an unwanted/ unplanned pregnancy, marriage because of the pregnancy, pregnancy perceived as a financial and emotional burden, conflict about the pregnancy between the woman and her husband, anger at his partner's decreased energy and ability to care for the abuse, ambivalent about the pregnancy, resentment because of increased responsibilities associated with a child/ another child, angry because the pregnancy makes her less attractive to him, frustrated because the pregnancy may change her sexual behavior toward him, anger about her need to reduce her workload or take maternity leave. ${ }^{13,14,33}$ The proportion of women experiencing violence during pregnancy is higher in women having three or more children, illiteracy, poverty, residing rural and Terai areas of Nepal. ${ }^{16,33,34}$ The violence during pregnancy threatens the goal of safe Motherhood for all women and consequently experience high maternal morbidity and mortality. ${ }^{4,15,33}$ On the other hand, man's violent behavior may worsen when his partner is pregnant and they have to do with the dominant image some men have of themselves which is challenged by the realization that women have capacities men cannot share and that society depends on women for its own survival through childbearing. In addition, pregnancy often limits sexual intercourse and may cause sexual frustration in the man. ${ }^{15,33}$ Spectacularly, an issue that has not as yet been resolved is whether pregnancy actually enhances the risk of domestic violence, or simply increases the chances to identify it through attendance at antenatal care. ${ }^{15,36}$ Abuse start during pregnancy and continue or change the pattern. Abuse are in different form like; control, limit, delay or deny her access to prenatal care; use her pregnancy as a weapon in emotional abuse by refusing sex on the grounds that her pregnant body appears unattractive to him, denying that the child is not his, refusing to support her during the pregnancy, refusing to support her during the childbirth; financially abuse by refusing her access to money to buy food and supplies; restrict her access to food; and force her to work beyond her endurance during pregnancy. $6,14,15,34$

Violence during pregnancy escalates during a women's gestation with serious consequences not only for the women but also for the fetus and ultimately for the child raising both the maternal and fetus adverse effects for example fetal death, low birth weight neonate, preterm delivery and small size for gestational age in fetus, and maternal mortality, mental health problems, kidney infections, less gain of weight during pregnancy and more likely to undergo operative delivery in pregnant women. ${ }^{6,15,36,36}$ The GBV during pregnancy is associated with the empowerment of women and has been highlighted as a significant problem that needs to be addressed by health care professionals. ${ }^{16,33}$

\section{Gender-based Violence in the Community level}

In the community, women can be subjected to sexual harassment at work, prostitution, pornography and trafficking. Additionally, migrant women are especially vulnerable given their minority and often illegal status. ${ }^{15,37}$ Female victims of sexual violence are considered as having lost their honor in the community. ${ }^{15,24} \mathrm{~A}$ girl's honor is perceived as a delicate asset that must be preserved, even at high cost, and if a girl fails to protect herself or gets victimized, not only she loses respect but also the family and even the entire village feel a sense of shame. As a consequence, there are cases where women have been doubly victimized for having reported violence they suffered and stigmatized within their own communities. ${ }^{16,24}$ Also, boys sleep with many girls and they remain prestigious but girls become (regarded as) prostitute. 13,33,38 Furthermore, widow women face much more problems than the women who are staying with her husband. $4,13,33,38$ Physical, sexual and psychological violence occur within the general community include battery, rape, sexual assault, sexual harassment and intimidation in school, in work, in transportation and in treatments. The exploitation and commercialization of women's bodies which is related to increased poverty, is mainly a result of unrestrained economic liberalism.

\section{Gender-based Violence in the State level}

Women are vulnerable to violence even by the State, whether in prisons or in situations of armed conflict, when rape is used as an instrument of war. ${ }^{17,40}$ One of the main obstacles for women seeking justice is limited, and in some places non-existent support structures for victims of sexual violence. ${ }^{38,40}$ Furthermore, the existing legal framework for addressing sexual violence has been criticized by human rights and other organizations as inadequate. Firstly, the definition of rape is narrow and focuses on issues of 'consent' rather than 'invasion of body'. Secondly, rape includes only penetration by sexual organ, and does not allow for other forms of penetration, such as oral sex or penetration by objects. Thirdly, the 35day statute of limitations is too short, especially where a victim is often too traumatized and frightened to come forward within such a short period of time. In cases where women do try to press charges, they often face pressure by the perpetrators and in some cases their communities to withdraw the charges in the name of social harmony. In some instances the police refuse to file a case because there is no medical report, while the doctor refuses to do a forensic examination in the absence of a First Information Report. ${ }^{24,41}$ The existence of complicated and expensive legal processes, where confidentiality is lacking, prevent women 
from seeking justice. ${ }^{42}$ Additionally, chauvinist attitudes that downplay the seriousness of violence against women also appear to influence decisions to arrest, prosecute and convict perpetrators. The apparent failure of the police and judicial system to support investigation and prosecution of cases of sexual violence reinforces the culture of impunity on which sexual violence thrives. Today, Nepal still lacks an integrated support model for victims of sexual violence, encompassing access to healthcare, psychosocial support and legal aid..$^{37,43}$ Besides, physical, sexual and psychological violence are too often perpetrated or tolerated by states extremely disturbing as regards women's right to their economic autonomy and their freedom of choice. Women are considered second class beings, of lesser value, hence, deprived of their fundamental rights.

The Government of Nepal has made significant improvements in the formulations of laws, policies and plan of actions after the end of historical Rana rule incorporating the gender-based violence issue in the first Civil Code 1964 and subsequent formulation and endorsement of laws, acts, action plans, policies and strategies. The efforts are Human Trafficking Control Act 1986; the Constitution of Nepal 1990; the National Plan of Action against Trafficking in Children and Their Commercial Sexual Exploitation 2001; the National Plan of Action against Trafficking in Children for Sexual and Labor Exploitation 2001; the National Plan of Action for Gender Equity and Women's Empowerment (Beijing Conference 1995). In addition, other endeavor are National Expert Committee's Recommendations on the implementation of CEDAW 2004; Women's Commission Act 2006; Interim Constitution of Nepal 2007; Human Trafficking (Control) Act 2007 (the restructuring of Human Trafficking Control Act 1986); the National Women's Commission five-year Strategic Plan 2009-2014; and the Domestic Violence (Offence and Penalties) Act 2009. But the implementation of those supporting entities is poor as a result there is high magnitude of gender-based violence in Nepal. ${ }^{44}$

\section{Gender-based Violence in the Conflict Situations}

At some point in armed-conflict situations, the right to life, the right to liberty and security of the person, the right to freedom from torture or cruel/ inhuman/ degrading punishment/ treatment, the right to be free from sexual violence, the right to peaceful assembly, and the right of children to special protection in armed conflict, including a prohibition on their recruitment into the armed forces are

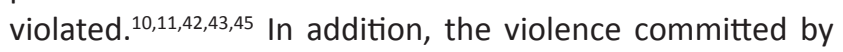
the state and the rebels increase including displacement, unlawful killing, torture, enforced disappearance, sexual violence and long-term arbitrary arrest from both the state and the rebel sides. ${ }^{24,43,46}$ During the conflict situation the sexual violence of girls and women increase immensely from both state security personnel and the rebels devastating their day to day works. ${ }^{40,49}$ Besides, internally displaced women, and women near army barracks, even trafficked or coerced for forced sex workers which goes up as a result of lack of economic security and support system..$^{39,48}$ In the conflict situation the sexual violence is committed by non-family members including parties to the conflict and the neighbors due to lack of or limited security systems at the community, absence of male members at home and increased authority of insurgents and armed forces, making them prime target of sexual and gender based violence. ${ }^{24,43,47,48}$ As a result, there exists 'conflict wives' phenomenon where such 'wives' were considered impure and immoral in the community once their 'protectors' left, resulting in ostracization and stigmatization for them and any children from the relationship. ${ }^{39}$ During the conflict, there is not only conflict-related sexual violence, but also non-sexual violence such as domestic violence for example captures of women and the girls by both the state security force and the rebel forces, hence, the needs and demands of the survivors should be looked at. ${ }^{37,48,49}$

\section{Special forms of Gender-based Violence in Nepal}

An unequal gender relation pervasive in the Nepalese society, has been a key in legitimizing violence against women. ${ }^{35,39}$ Besides, taboos surrounding sexual violence in Nepalese society and the general culture of silence are the biggest challenge to assess problem and endeavor accordingly making it difficult to document sexual violence without risk of causing harm to the victims. ${ }^{12,37,39}$ Studies in Nepal indicate that a strong patriarchal element lies at the heart of Nepalese society being reportedly at the

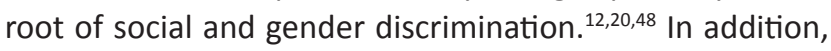
findings suggest that patriarchal attitudes and deep-rooted stereotypes that discriminate against women remain entrenched in the social, cultural, religious, economic/ political institutions, structures of Nepalese society, and in the media, thereby, legitimating the same. ${ }^{41,50}$ Violence against women is socially accepted as 'normal' and remains high in Nepal. ${ }^{12,20,42}$ Furthermore, women from Muslim community are not culturally allowed to participate in a range of social activities. ${ }^{12,50}$ Some of the socially ill practices have instigated to the vulnerable status of women and children such as child marriage; dowry system: offering cash or kind during wedding; Deuki: an ancient custom practiced in the far western regions of Nepal in which a young girl is offered to the local Hindu temple to gain religious merit; Jhuma: a tradition of offering the second daughter to the monastery in the Himalaya region of Nepal; Chaupadi: tenting women in a segregated and unhygienic huts during menstrual period in mid-western and far-western region of Nepal, Badi: a low sub-castes traditionally practicing prostitution; Kumari: the girl who is worshipped is not allowed to go out of the temple where she is worshipped until puberty after that they are replaced by another Kumari but she should not marry for lifelong; and Kamlari: sending girl bonded-labour are still prevalent in Nepalese societies. ${ }^{20,41,42,50}$ Among them, Deuki, Jhuma, Chhaupadi and Kamlari experience all types of violence frequently and consequently encounter more physical and mental health problems. ${ }^{20,42,51}$ 


\section{IMPERATIVE IMPLICATION}

At the moment, it is time to set strategies as to provide help to the victims of violence developing the mechanism to identify them, enhance social support, conduct screening and referral of victims, implement behavioral interventions, implement improve legal provisions and the research so that gender-based violence is totally eliminated with collaboration between the government and civil society including the community. ${ }^{4,8,13,15,16,45}$ This initiative should be to ensure the safety and autonomy of the violence survivors' assuring the relevance and appropriateness to the local setting. 2,23,33 Constitution of Nepal guarantees the right to constitutional remedy for those whose fundamental rights have been violated as has explicitly prohibited all forms of discrimination on the ground of gender declaring GBV a crime and has commitment to eliminate all forms of GBVs and ensure gender equality by ratifying the UN Convention on the Elimination of All Forms of Discrimination Against Women (CEDAW) and several other related international instruments but due to the absence of strict implementation of these instruments GBVs recurrently happen. Although Nepal ratified the CEDAW and formulated Domestic Violence Act and a 5-year national strategy and action plan for ending gender-based violence, and put the GBV in place the strong normative

\section{REFERENCES}

1. UNIFEM. UNIFEM's Partnerships with Regional Organizations to Advance Gender Equality; 2009.

2. USAID. Addressing Gender-Based Violence through USAID's Health Programs: A Guide for Health Sector Program Officers; July 2006.

3. Krug EG, Mercy JA, Dahlberg LL, Zwi AB. The world report on violence and health. Lancet 2002;360:1083-8.

4. Heise L. Gender-based Abuse: The Global Epidemic. Cad Saúde Públ, Rio de Janeiro 1994;10((suppl 1)):135-45.

5. Ragnarsson A, Townsend L, Ekstro"m AM, Chopra M, Thorson A. The construction of an idealised urban masculinity among men with concurrent sexual partners in a South African township Global Health Action 2010;3(5092):1-7.

6. Cook J, Bewley S. Acknowledging a persistent truth: domestic violence in pregnancy. J R Soc Med 2008;101:358-63.

7. Pitpitan EV, Kalichman SC, Eaton LA, Cain D, Sikkema KJ, Skinner D, $\mathrm{MH}$, Watt, Pieterse D. Gender-based violence, alcohol use, and sexual risk among female patrons of drinking venues in Cape Town, South Africa. J Behav Med 2012.

8. The Rising Nepal. Ending Domestic Violence. [2012]. http://www. gorkhapatra.org.np/rising.detail.php?article_id $=55434 \&$ cat_id $=7$ Editorial (serial on the Internet).

9. USAID. Gender-Based Violence: Impediment to Reproductive Health; 2010. Available from: http://www.igwg.org/igwg_media/gbvimpediment-to-RH.pdf.

10. 1UN. United Nations General Assembly: Declaration on the elimination of violence against women. New York: United Nation 1993.

11. Population Council. Sexual and Gender-based Violence in Africa: Literature Review. Nairobi: Population Council Sub-Sararan Africa Region; February 2008. and legal commitments to ending gender-based violence and legal binding itself to put the CEDAW provisions into practice, still there are setbacks in the implementation of these commitments. The latest NDHS 2011 incorporated GBV as an issue of assessment. Furthermore, there are only a few researches conducted on GBVs and no research covering all geographical areas and ecological regions is being held yet. ${ }^{52-54}$ Thus, more researches in this area are anticipated.

\section{CONCLUSION}

GBVs remain one of the most serious social, legal and health challenges for the 21st century. It is a major public health problem and has a serious impact on women's health and well-being. It is one of the indispensable issues of equity and social justice. It happens in all the settings like family, community and state hence, has to be dealt with involving all the sectors. Much work remains to be done to create an environment free of gender-based violence. Raising awareness level of all the settings involving all the mechanisms of society have to be encouraged. Concerning to the current victims, a mechanism has to be developed for identifying, enhancing social support, screening and referral and legal provisions.

12. Upadhayay CK. Country Presentation on Gender Based Violence in Nepal: Presented in Gender Based violence Re-examine Workshop Philippines. Kathmandu Nepal 2010 Oct 14: 24-13.

13. Heise L, Ellsberg M, Gottmoeller M. A global overview of genderbased violence. International Journal of Gynecology and Obstetrics 2002;78(1):S5-S14.

14. Jamieson BL. A Handbook for Health and Social Service Professionals Responding to Abuse During Pregnancy. Ottawa, Ontario, K1A 1B4, Canada: Minister of Public Works and Government Services Canada; 1999.

15. Benagiano G, Carrara S, Filippi V. Social and ethical determinants of human sexuality: 2. Gender-based violence. The European Journal of Contraception and Reproductive Health Care August 2010;15:220-31.

16. Ministry of Health and Population (MOHP) [Nepal] NE, and ICF International Inc. Nepal Demographic and Health Survey 2011 Kathmandu, Nepal; March 2012.

17. Karmaliani R. HS, Hirani S, Asad N, Cassum L. Violence against Women in Pakistan: Contributing Factors and New Interventions. Mental Health Nursing 2012;33:820-6.

18. Lee-Koo K. Gender-Based Violence Against Civilian Women in Postinvasion Iraq: (Re) Politicizing George W. Bush's Silent Legacy. Violence Against Women 2011;17(12):1619-34.

19. Kalisya LM, Justin PL, Kimona C, Nyavandu K, Eugenie MK, Lusi Jonathan KM et.al. Sexual Violence toward Children and Youth in War-Torn Eastern Democratic Republic of Congo. PLOS ONE January 18, 2011;6(1):e15911.

20. Sharma S. Domestic violence in Nepali society: Root Cause and Consequences A research report. KathmanduMay 2007.

21. Pandey S, Lin Y. Adjusted Effects of Domestic Violence, Tobacco use, and Indoor Air Pollution from Use of Solid Fuel on Child Mortality. Matern Child Health J ;13 Oct 2012. 
22. Lang DL, Salazar LF, DiClemente RJ, Markosyan K. Gender Based Violence as a Risk Factor for HIV-Associated Risk Behaviors Among Female Sex Workers in Armenia. AIDS Behav 2013;17:551-8.

23. Kelly JT, Betancourt TS, Mukwege D, Lipton R, VanRooyen MJ. Experiences of female survivors of sexual violence in eastern Democratic Republic of the Congo: a mixed-methods study. Conflict and Health 2011;5(25):1-8.

24. UNHCR. An analysis of conflict-related violations of international human rights law and international humanitarian law between February 1996 and 21 November 2006. Geneva; 2012.

25. Rahman M, Nakamura K, Seino K, Kizuki M. Intimate partner violence and use of reproductive health services among married women: evidence from a national Bangladeshi sample. BMC Public Health 2012;12(913):1-12.

26. Hayati EN, Högberg U, Hakimi M, Ellsberg MC, Emmelin M. Behind the silence of harmony: risk factors for physical and sexual violence among women in rural Indonesia BMC Women?'?s Health 2011;11(52):1-8.

27. Martin LS, Moracco KE, Garro J, Tsul AO, Kupper LL, Chase JL et.al. Domestic violence across generations: Findings from northern India. International Journal of Epidemiology 2002;31:560-72.

28. Maman S, Yamanis T, Kouyoumdjian F, Watt M, Mbwambo J. Intimate Partner Violence and the Association With HIV Risk Behaviors Among Young Men in Dar es Salaam, Tanzania. Journal of Interpersonal Violence 2010;25(10):1855-72.

29. Laisser RM, Nystro“m L, Lindmark G, Lugina HI, Emmelin M. Screening of women for intimate partner violence: a pilot intervention at an outpatient department in Tanzania. Global Health Action 2011;4(7288):1-12

30. Shrivastava PS, Shrivastava SR. A Study of Spousal Domestic Violence in an Urban Slum of Mumbai. Int J Prev Med. January 2013 4(1):2732.

31. Simkhada B, van Teijlingen ER, Porter M, Simkhada P. Factors affecting the utilization of antenatal care in developing countries: systematic review of the literature. Journal of Advanced Nursing 12 October 2007;61(3):244-60.

32. Simkhada B, Porter MA, van Teijlingen ER. The role of mothers-in-law in antenatal care decision-making in Nepal: a qualitative study. BMC Pregnancy and Childbirth 2010;10(34).

33. Perera J, Gunawardane N, Jayasuriya V. Review of Research Evidence on Gender Based Violence (GBV) in Sri Lanka; 2011.

34. Ray AM, Salihu HM. The impact of maternal mortality interventions using traditional birth attendants and village midwives J Obstet Gynaecol January 2004;24(1):5-11.

35. Nasreen HE, Kabir ZN, Forsell YEdhborg M. Prevalence and associated factors of depressive and anxiety symptoms during pregnancy: A population based study in rural Bangladesh. BMC Women?'?s Health 2011;11(22):1-9.

36. UNCT-Nepal. Joint UNCT Input on Nepal for the Report of the Secretary General to the Security Council on the Implementation of SCR 1820 on Women, Peace and Security April 2009. Kathmandu: UNCT-Nepal; April 2009.
37. Regmi PR, van Teijlingen ER, Simkhada P, Acharya DR. "Boys Remain Prestigious, Girls Become Prostitutes": Socio-Cultural Context of Relationships and Sex among Young People in Nepal. Global Journal of Health Science April 2010; 2(1):60-72.

38. WOREC. Violence against Women in Nepal: A Complex and Invisible Reality. Kathmandu; 2006.

39. UNIFEM. Women, War, Peace [internet].

40. Concluding Observations on GBV: Nepal. Kathmandu; 2008

41. WOREC. Adolescents and Youth Speak about Violence and its Impact: A Case Study in Eastern Nepal. Kathmandu; 2003.

42. UNFPA C. Victim of a rape in 2002 speaking to OHCHR-Nepal, during the assessment mission in Achham District. Kathmandu; May 2009.

43. Stark L, Ager A. A Systematic Review of Prevalence Studies of GenderBased Violence in Complex Emergencies. Trauma, Violence, and Abuse 2011;12(3):127-34.

44. Joshi SK, Swahnberg K. Trafficking of Women and Girls from Nepal to India for Prostitution: What is Known About its History, Nurturing Factors, Health Effects and Prevention? Nurturing Factors, Health Effects and Prevention 2010.

45. Keygnaert I, Vettenburg N, Temmerman M. Hidden violence is silent rape: sexual and gender-based violence in refugees, asylum seekers and undocumented migrants in Belgium and the Netherlands. Culture, Health \& Sexuality. May 2012;14(5):505-20.

46. Putnam FW. Ten-Year Research Update Review: Child Sexual Abuse. $J$ Am Acad Child Adolesc Psychiatry March 2003;42(3):269-78.

47. UNIFEM S. Sexual and Gender Based Violence during Conflict and Traditional Period: Jhapa and Morang Districts: A Research Report. Kathmandu; 2008.

48. Orach CG, Musoba N, Byamukama N, Mutambi R, Aporomon JF, Luyombo $A$ et.al. Perceptions about human rights, sexual and reproductive health services by internally displaced persons in northern Uganda. African Health Sciences October 2009;9(special issue 2 ):s72-s80.

49. FWLD. Domestic Violence against Women in Nepal: Concept, History and Existing Laws. Kathmandu; 2008.

50. Third Eye Volunteer in Nepal. Special forms of gender-based violence in Nepla [cited 2013 March 22]. Available from: http:// volunteersummernepal.org/deuki-pratha.

51. GoN, editor. Interim Constitution of Nepal Kathmandu: Government of Nepal; 2007.

52. Josh SK, Swahnberg K. Women and girls trafficking from Nepal to India for prostitution: what is known about its history, nurturing factors, health effects, and prevention?2012.

53. Joshi SK, Kharel J. Violence against Women in Nepal -- An Overview. The Free Library [serial on the Internet] 2008. Available from: http:// www.thefreelibrary.com/Violence Against Women in Nepal -- An Overview-a01073875052.

54. Joshi SK. Violence against women in Nepal: Role of health care workers. Kathmandu Univ Med J 2009;7 (2)(26): 89-90. 